\title{
Editorial (ERPP issue 9.3)
}

\author{
Oon Seng Tan
}

Received: 19 August 2010 / Accepted: 20 August 2010 / Published online: 4 September 2010

(C) Springer Science+Business Media B.V. 2010

Issue 9.3 of the Educational Research for Policy and Practice (ERPP) presents several pieces of research from the perspectives of policy and practice from Nepal, China, Australia and the United States.

In the paper by Peshal Khanal, the author explores the issue of school decentralisation policy in Nepal. While this policy has been implemented for more than 8 years with the financial and technical assistance of the World Bank, confusion and controversy have been prevalent in relation to its goals, outcomes and sustainability. This article first summarises the Bank's approach to decentralisation and then examines the local issues against the macro-level advocacy of education decentralisation. It reveals that there are significant variances between the Bank's vision on school decentralisation and the realities which confront its implementation at the local level. The article concludes that accommodating the interest of diverse stakeholders, change in traditional bureaucratic culture in government offices and contextualising the global policy in a local context are major issues for addressing the existing discrepancies between the macro-level advocacy and micro-level reality.

The next paper is contributed by Kusum Singh, Mido Chang and Sandra Dika. The authors examine the relationship of self-concept, school belonging and school engagement to school performance of Caucasian- and African-American students in the United States. The main purpose is to assess the ethnicity-based differences in these psycho-social constructs and to explore their differential relationship to school achievement in high-school students from different ethnic background. The data were collected through a survey questionnaire in three school divisions in the Southwest region of Virginia. The results showed significant ethnicity-based difference in self-concept and in school engagement, but no significant difference in school belonging. The achievement differences were also significant, Caucasian students being higher on self-reported grades. In the regression model, self-concept was not a significant predictor of school outcomes, while school belonging had a significant relationship to school achievement for African-American students. Both self-concept and school

O. S. Tan $(\bowtie)$

National Institute of Education, Nanyang Technological University, Singapore, Singapore

e-mail: oonseng.tan@nie.edu.sg 
engagement were significant for Caucasian students. The authors also discuss some policyrelevant implications of the research in the paper.

In the third paper, Rice posits that one of the most powerful school-level factors that have an impact on student learning is the effectiveness of the teacher. Effective teachers are, therefore, needed to lift the achievement of socio-economically disadvantaged students and improve equity, and policy must be designed in such a way as to draw more of them to the most disadvantaged educational settings. To do this, systems and schools need to be aware of differences in the priorities more and less effective teachers hold in deciding where to teach. Rice's study highlighted such differences in a large sample of Australian teachers. In the study, the most effective teachers placed considerably more importance on professional factors in determining whether to transfer into a school. Implications for staffing policy are discussed in the paper.

The paper by $\mathrm{Xu}$ Yang tries to identify the causes and implications of under-representation of the rural-poor students in China's higher educational institutions. According to the author, China is now facing significant challenges in funding its rapidly expanding higher education systems, though it has experienced enormous economic growth in recent years. Equity has become a serious concern in Chinese higher education system. This article identifies academic and social preparedness, institutional funding arrangements, the admissions policy and the socio-economic background as significant factors that determine an individual's opportunity to access to higher education in China. A brief discussion of possible policy recommendations is also presented.

We hope that the papers will generate further discussions and collaborations among educators and researchers so that good educational philosophies and practices may be shared globally. We look forward to your valuable contributions to the ERPP. 